\title{
Acute mechanical intestinal obstruction due to foreign body ingestion
}

\author{
Emin Uysal*, Hakan Çelik*, Şakir Ömür Hıncal*, Kenan Ahmet Türkdoğan*, \\ *Department of Emergency Medicine, University of Health Sciences, Bagcilar Training and Research \\ Hospital, Istanbul, Turkey
}

doi.org/10.33706/jemcr.601323

\begin{abstract}
Introduction: Foreign body ingestion usually occurs accidentally and is a common condition in childhood, but it is rarely seen in adults and is frequently encountered in people with mental retardation and psychiatric disease. The outcome is usually defecation of the ingested materials but rarely requires surgical intervention.

Case Report: A 33-year-old male patient was admitted to the emergency department with the complaint of constipation as a result of swallowing about 1000 plastic buttons yesterday. His acute mechanical intestinal obstruction was alleviated with conservative treatment and the patient discharged with recommendations.

Conclusion: The number, shape, size, and time of ingestion determine the mode of treatment. There are three main principles in treatment. Endoscopic retraction, conservative follow-up and surgical intervention. Also, tomography should be considered as an option for foreign bodies that can not be visualized with direct radiography.
\end{abstract}

Keywords: Acute mechanical intestinal obstruction, foreign body ingestion, emergency department non-penetrating blunt trauma

\section{Introduction}

Foreign body ingestion is one of the most common reasons for admission to hospitals throughout the world. Swallowing of foreign bodies is usually seen in adults in the presence of mental or psychiatric disorders. Most of the swallowed objects are excreted spontaneously from the gastrointestinal tract without causing any problems, It should be removed by endoscopy in 10 to $20 \%$ of cases (1). Surgical intervention is required because of mechanical bowel obstruction, fistula and perforation develop in only $1 \%$ of the cases $(2,3)$. The size, type, shape, number, and duration of the ingested body are the most important factors in determining the type of treatment. Due to the diversity of the ingested objects, the anatomical and physiological characteristics of the individuals, a definitive treatment algorithm for the indication of surgical intervention cannot be established.

\section{Case Presentation}

A 33-year-old male patient was admitted to the emergency department with abdominal pain and constipation. One day ago, it was learned that he had swallowed about 1000 plastic buttons due to the claim. There was no feature in his medical history. The patient's general condition was stable and his vital signs were stable. Physical examination revealed minimal tenderness in the abdomen with palpation. Intense gas was detected on direct abdominal X-ray (Figure 1). Contrastenhanced abdominal computed tomography of the patient showed bright opacities in the 
stomach, small intestine and colon compatible with the adjacent foreign body, 1

${ }^{*} 1 \mathrm{~cm}$ in size (Figure 2).

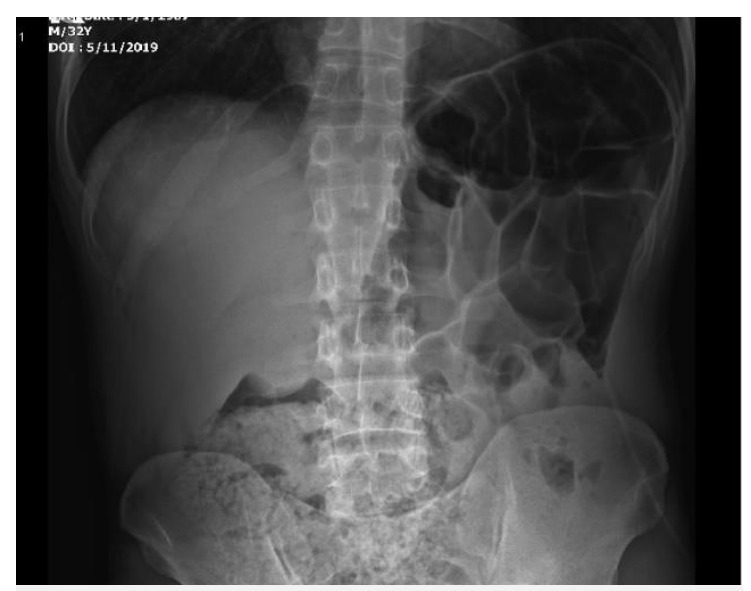

FIGURE 1. Direct abdominal X-rav of the patient.

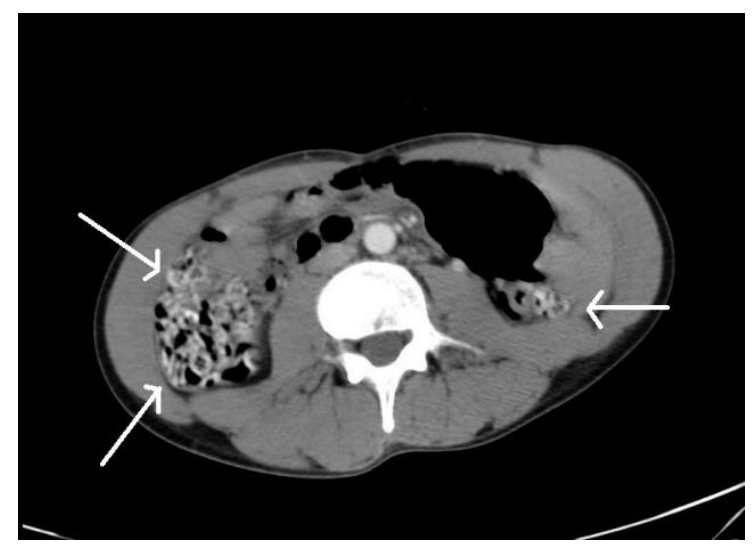

FIGURE 2. Opacity foreign bodies on contrast-enhanced abdominal computed tomographv.

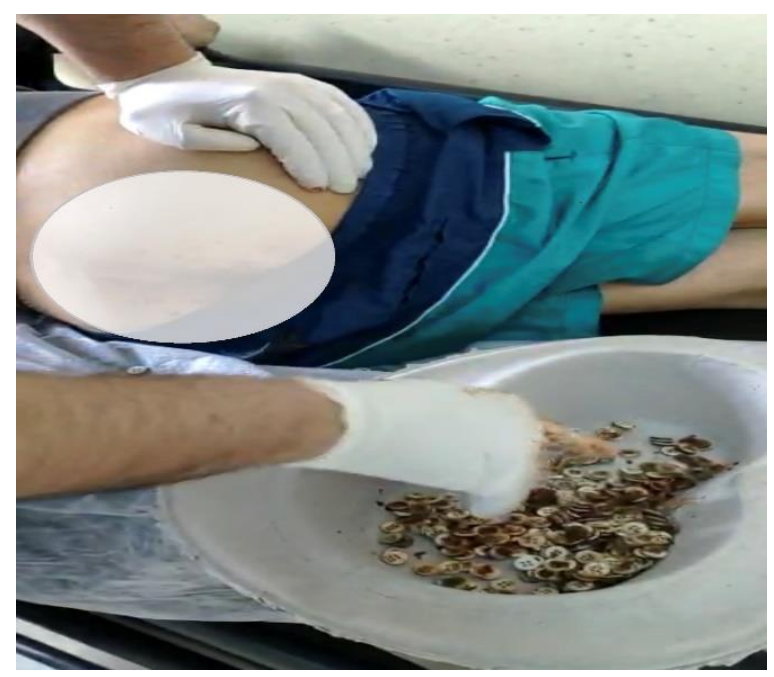

FIGURE 3. Foreign bodies removed from the rectum.
Most of these foreign bodies were removed with rectal touch (Figure 3). The patient was followed-up for observation and fiber-rich aqueous soft food was started. During the 24hour observation period, the patient removed the gas-stool outlet as well as the remaining foreign bodies and was discharged 3 days later by suggesting outpatient control.

\section{Discussion}

In adults, foreign body ingestion is usually associated with mental retardation, drinking alcohol, or psychiatric disorders (4). Although there is no statistical study performed in our country in terms of incidence and demographic characteristics of foreign body swallows, the number of cases admitted to our hospitals is remarkably high. Direct radiography is used to investigate the swallowed foreign body. Although ingested objects vary according to their structure, they often appear if they are radiopaque. Also, direct X-ray can give information about the number, shape, and localization of the gastrointestinal tract (5-7). Tomography may be considered for foreign bodies that cannot be seen by direct radiography. The case mentioned in this report was mentally normal, his general condition and vital signs were stable as well. We took abdominal $\mathrm{x}$-ray after the determination of the pain and tenderness in the abdominal exam. In our patient, foreign bodies that could not be seen by direct radiography were detected by tomography. Treatment methods should be determined according to the shape, number, size, and duration of the ingested body. There are three main principles in treatment. Endoscopic retraction, conservative follow-up and surgical intervention. If the foreign body is in the stomach, endoscopic removal is the method that should be tried first. If endoscopy is not possible, conservative follow-up should be taken if the small body or small intestine is considered. In general, it is recommended to remove the body by gastrotomy in these cases since it is difficult to pass objects over $7 \mathrm{~cm}(2,8)$. There is a high risk of perforation, especially with thin, sharp and sharp objects, so these patients should be closely monitored. (9). While $80 \%$ of the foreign bodies are spontaneously separated from the 
gastrointestinal tract (GIS), $10-20 \%$ of the clinics need endoscopic procedures. (10). In our patient, foreign bodies were removed with rectal touch without surgical procedure.

\section{Conclusion}

The negative clinical symptoms/signs and unremarkable plain film on the initial consult could mislead the initial attending physician, which result in a delay of proper management. Considering the size, number, shape, structure and time of ingestion of the ingested foreign body, it should be decided which endoscopic retrieval, conservative follow-up or surgical intervention should be chosen. Surgical intervention is inevitable in the presence of complications such as bleeding, obstruction or puncture.

\section{REFERENCES}

1.Hernández Anselmi E, Gutiérrez San Román $C$, Barrios Fontoba JE, Ayuso González L, Valdés Dieguez E, Lluna González J, et al. Intestinal perfo $\neg$ ration caused by magnetic toys. J Pediatr Surg. 2007;42(3):E13-6.

2.Velitchkov NG, Grigorov GI, Losanoff JE, Kjossev KT. Ingested foreign bodies of the gastrointestinal tract: retrospective analysis of 542 cases. World J Surg. 1996;20(8):1001-5.

3.Kay M, Wyllie R. Pediatric foreign bodies and their management. Curr Gastroenterol Rep. 2005;7:212-8.

4.Rodriguez-Hermosa JI, Codina-Cazador A, Sirvent JM, Martin A, Girones J, Garsot E. Surgically treated perforation of the gastrointestinal tract due to ingested foreign bodies. Colorectal Dis. 2008;10(7):701-7.

5.Wyllie R. Foreign bodies in the gastrointestinal tract. Curr Opin Pediatr. 2006;18(05):563-4.

6.Ikenberry SO, Jue TL, Anderson MA, et al. Management of ingested foreign bodies and food impactions. Gastrointest Endosc. 2011;73(06):1085-91.

7.Webb WA. Management of foreign bodies of the upper gastrointestinal tract: update. Gastrointest Endosc. 1995;41(1):39-51.

8.Vagner EA, Subbotin VM, Davidov MI, Repin VN, Titlianova ZA, Vorontsov AP. Surgical policy in gastrointestinal tract foreign bodies. Khirurgiia (Mosk). 1999;(5):24-8.

9.Başpinar I, Sahin S, Erdoğan G. Acute mechanical intestinal obstruction after ingestion of foreign bodies: a case report. Ulus Travma Acil Cerrahi Derg. 2010;16(1):924.

10.R Bademci, ÖÖ Bayar, S Zeren, E Sobutay, A Akan, G Yavuz, Y Eryavuz. Yutulan İğnenin Karın İçindeki Hareketi: Olgu Sunumu. Okmeydanı Tıp Dergisi 2014;30(2):101-4.

\section{Funding: None Declared}

\section{Conflict of Interest: None Declared}

Corresponding Author: Emin Uysal, MD

Department of Emergency Medicine, University of Health Sciences, Bagcilar Training and Research Hospital, 34100, Bagcilar, Istanbul, Turkey. dreminuysal@hotmail.com 